\title{
P018 - Safety road for children: knowledge and attitudes of parents in the use of child restraint systems
}

\author{
Helena Fernandes (Portugal); Graça Aparício (Portugal)²
}

${ }^{1}$ Centro Hospitalar de Trás-os-Montes e Alto Douro - Hospital Vila Real, Unidade de Neonatologia; ${ }^{2}$ Polytechnic Institute of Viseu/Health School

Theme: Child protection and managing risk.

Keywords: Road safety, child restraint systems, parents' knowledge.

Background: Correct use of a restraint system for children (CRS) from birth is an effective form of protection.

Objectives: To characterize parent's knowledge and attitudes in using CRS.

Methods: Cross-sectional study, held in a non-probabilistic sample of 112 parents of newborns, mothers mean age 30.37 years old $(S D=5.63)$. Parents completed a questionnaire, 24-48 hours after baby birth in Obstetrics and Neonatology services of a public hospital in Portugal.

Results: Mothers mostly had secondary level of education. In 54.5\% CRS was part of the 'layette baby' and, of these, $72.3 \%$ had already experimented it in the car. Only $15.2 \%$ reported having had training by nursing team during pregnancy. $97.3 \%$ intended to use the CRS, however only $47.3 \%$ would do it adequately. All recognize that CRS prevents serious injury, and $67 \%$ reported adequate knowledge.

Conclusions: Results indicate that knowledge and parental attitudes about the proper use of CRS remains insufficient.

\section{P019 - Developing a pain scale for infants in collaboration with clinical staff in the neonatal intensive care unit}

Tarja Pölkki (Finland) ${ }^{1}$; Anne Korhonen (Finland)2; Ulla Heikkinen (Finland) ${ }^{2}$; Anna-Kaija Palomaa (Finland)²; Seija Miettinen $(\text { Finland })^{2}$

${ }^{1}$ Institute of Health Sciences, University of Oulu; ${ }^{2}$ Department of Paediatrics and Adolescence, Oulu University Hospital

Theme: Multidisciplinary team working. 